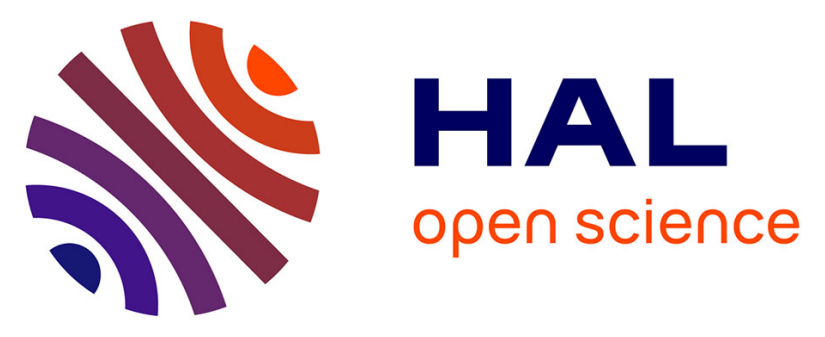

\title{
On the co-integration of a thermo-resistive flow-rate sensor in a multi-parameter sensing chip for water network monitoring
}

Shaun Ferdous, E. Nefzaoui, Hugo Regina, William Cesar, Frederic Marty, Martine Capochichi-Gnambodoe, Patrick Poulichet, Philippe Basset, Francesco Peressuti, Sreyash Sarkar, et al.

\section{To cite this version:}

Shaun Ferdous, E. Nefzaoui, Hugo Regina, William Cesar, Frederic Marty, et al.. On the co-integration of a thermo-resistive flow-rate sensor in a multi-parameter sensing chip for water network monitoring . 19th International Conference on Solid-State Sensors, Actuators and Microsystems (TRANSDUCERS 2017), Jun 2017, Kaohsiung, Taiwan. pp.1069-1072, 10.1109/TRANSDUCERS.2017.7994237 . hal01578963

\section{HAL Id: hal-01578963 \\ https://hal.science/hal-01578963}

Submitted on 30 Aug 2017

HAL is a multi-disciplinary open access archive for the deposit and dissemination of scientific research documents, whether they are published or not. The documents may come from teaching and research institutions in France or abroad, or from public or private research centers.
L'archive ouverte pluridisciplinaire HAL, est destinée au dépôt et à la diffusion de documents scientifiques de niveau recherche, publiés ou non, émanant des établissements d'enseignement et de recherche français ou étrangers, des laboratoires publics ou privés. 


\title{
ON THE CO-INTEGRATION OF A THERMO-RESISTIVE FLOW-RATE SENSOR IN A MULTI-PARAMETER SENSING CHIP FOR WATER NETWORK MONITORING
}

\author{
Ferdous Shaun ${ }^{1}$, Elyes Nefzaoui ${ }^{1}$, Hugo Regina ${ }^{1}$, William Cesar ${ }^{2}$, Frederic Marty ${ }^{1}$, Martine \\ Capochichi-Gnambodoe ${ }^{I}$, Patrick Poulichet ${ }^{l}$, Philippe Basset, Francesco Peressuti ${ }^{l}$, Sreyash \\ Sarkar ${ }^{l}$, Tarik Bourouina ${ }^{1}$ \\ ${ }^{1}$ Université Paris-Est, ESYCOM Lab, ESIEE-Paris, Noisy-Le-Grand, France \\ ${ }^{2}$ Fluigent, 1, Mail du Professeur Mathé, Ville Juif, France \\ *Ferdous Shaun, ferdousjahan.shaun@esiee.fr
}

\begin{abstract}
Motivated by the need for a multi-parameter sensing chip for water networks monitoring, we address here the specific case of a flow-rate sensor where the main challenge is the substrate material. Instead of using conventional low thermal conductivity materials such as glass, silicon has to be used. Indeed, a silicon substrate enables the co-integration of various kinds of sensors on the same chip as reported in this contribution. However, it increases the flow-rate sensor power consumption due to larger thermal leaks. We therefore design and study an optimized low power micro-machined thermal flow-rate sensor based on a silicon substrate and operating according to hot-wire anemometry. It can be considered as an alternative to other well established sensors for liquid flow-rate measurement when both the use of a silicon substrate and a low power consumption are needed.
\end{abstract}

\section{KEYWORDS}

Thermal Flow-Rate sensor, MEMS, low power consumption

\section{INTRODUCTION}

Precise flow-rate measurement is of paramount importance in different fields of science and engineering like- Environmental monitoring [1], R\&D [2], Biology [3] and Bio-medical $[4,5]$. This is particularly the case for water networks monitoring systems, where the flow-rate measurement is important for measuring water consumption. Furthermore, additional parameters measurements such as pressure, temperature and electrical conductivity are often needed for leakage detection and water quality assessment. It is therefore tempting to cointegrate all those sensors on the same chip so as to provide a monolithic multi-parameter sensing solution.

Generally, a water distribution system is an extensive network. Consequently, a finely meshed monitoring system based on a sensor network can be very costly. Micro-fabrication technologies offer solutions for such a problem with a good meshing/cost tradeoff through labon-chip sensors, which can be deployed in large number. During the last decades, the advancement of microfabrication techniques enabled the design of low cost miniaturized sensors for different applications $[5,6]$. These sensors offer several advantages: compactness, low cost and low power consumption.

In the particular case of thermal flow-rate sensors, most of the existing designs are made on glass substrates $[2,7]$ in order to reduce heat leakage and minimize the hot wire consumption. In our case, multi-parameter sensors cointegration is a main goal. On the other hand, the pressure sensor requires a silicon substrate. Consequently, the use of a silicon substrate for the flow-rate sensor is a main constraint that will be tackled in the present paper while targeting both large sensitivity and low power consumption.

\section{FABRICATION}

The multi-parameter sensor (Figs. 1 and 2) has a MEMS chip size of $1 \times 1 \mathrm{~cm}$ in which the footprint of each sensor is no more than a few millimeters.

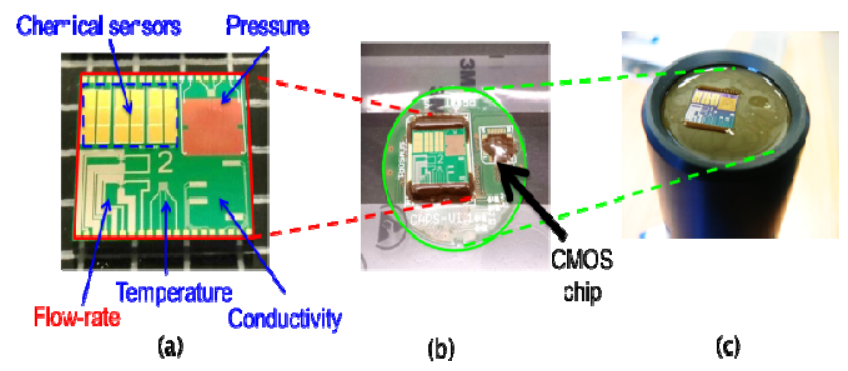

Figure 1: Multi-parameter sensor for water networks monitoring. (a) The MEMS chip co-integrating 4 physical and 5 chemical sensors; capsule board with MEMS and CMOS chips, (c) sensor head.

All sensors are based on resistive read-out and all of them, except the pressure sensor, are easily obtained by metal micro-patterning with the combination of titanium, platinum and gold. Hence, when using glass as a substrate material, flow-rate sensors are easily co-integrated with temperature and water conductivity sensors. When using silicon as a substrate material, further co-integration of a pressure sensor requires additional steps, which include patterning of polysilicon strain gauges and backside etching of the silicon bulk. This last step is also used to produce thin silicon membranes, for both the pressure sensor and some prototypes of the flow-rate sensor. In the former, the membrane acts as a mechanically flexible structure. In the latter, it also contributes to the heater thermal insulation. 

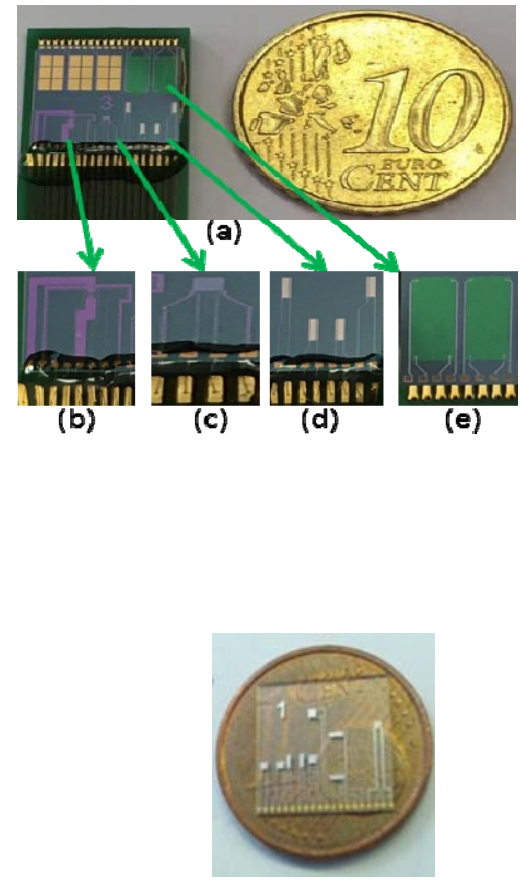

(f)
Figure 2: Details of (a) fabricated silicon multiparameter sensor chip including (b) flow-rate sensor, (c) temperature sensor, (d) 2 conductivity sensors, (e)2 pressure sensors, (f) Similar chip on glass substrate cointegrating all sensors except the pressure sensor.

\section{EXPERIMENTAL SETUP}

The experimental setup is shown in Figure 3. The sensor is inserted into a $32-\mathrm{mm}$ diameter T-junction PVC pipe. A square-shaped plastic box with one open side is used as a free surface water reservoir in which a variable speed water pump is submerged. Two pieces of a $16-\mathrm{mm}$ diameter flexible PVC pipe are used to build the closed water loop including the water reservoir and the $\mathrm{T}$ junction containing the sensor chip. Two pipe diameter adapters are used to connect the 32-mm T-junction pipe to the 16-mm flexible pipes.

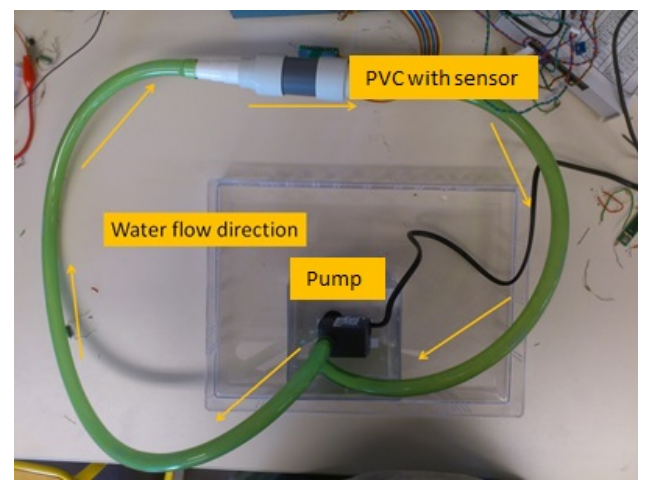

Figure 3: experimental setup for flow-rate sensors characterization.

Hot-wire anemometric operation scheme is used for velocity and flow-rate measurements. To ensure a good anemometric operation, a constant current source is used to supply the current to the 4-probe heater resistor, i.e. to the hot wire. LabVIEW is used for data acquisition. At a given flow-rate, the resistor is cooled down. The temperature drop induces a drop of the resistance value. The voltage drop at the resistor terminals is measured. The resistance drop with respect to the zero-velocity situation is then calculated and related to the temperature drop and hence to the fluid velocity.

\section{MODELING AND SIMULATION}

Computational Fluid Dynamics (CFD) simulations were carried out in order to perform a parametric study of different geometric and materials properties on the device performances. The simulation was done with COMSOL 5.2a using conjugate heat transfer physics which takes into account the heat transfer both in the solid and fluid media. All the materials properties were imported from

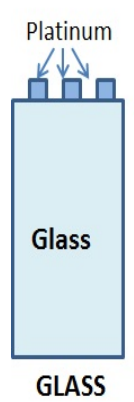

(a)

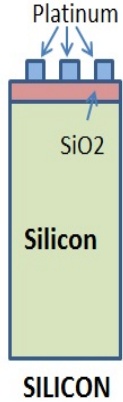

(b)

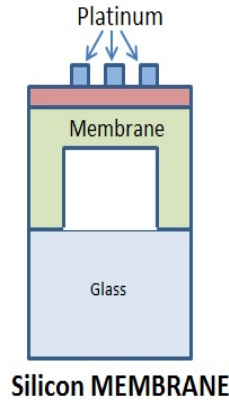

(c)

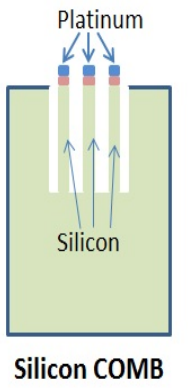

(d)
Figure 4: The 4 different configurations considered for the flow-rate sensor aiming to study the impact on thermal conductance and hence on power consumption

the COMSOL material library. We show in Figure 4 a schematic of the different geometries considered during the simulation task. The schematic includes the geometries of three existing flow-rate sensors: on glass substrate, on silicon substrate and on silicon membrane (Figure 4 (a), (b) and (c), respectively). It also shows a new optimized design ((Figure 4 (d)) named comb hereafter. A parametric study was conducted to find out the optimal aspect ratio of the cavity and the pillars of the comb structure. The cavity height and width range from 50 to $300 \mu \mathrm{m}$ and 100 to $1000 \mu \mathrm{m}$, respectively. The pillar height is equal to the cavity depth while its width is equal to the platinum resistor width which ranges between $5 \mu \mathrm{m}$ and $10 \mu \mathrm{m}$. In the different configurations, the substrate, either glass or silicon, is $500 \mu \mathrm{m}$-thick. A 0.45 $\mu \mathrm{m}$-thick silicon dioxide insulation layer is systematically used on top of the substrate. Finally, a $0.3 \mu \mathrm{m}$-thick and $106 \mu \mathrm{m}$-long rectangular platinum wire is used as the flow-rate sensor hot-wire.

The simulation is carried out over a large water domain where the sensor chip is submerged to avoid side effects. Constant temperature boundary conditions are considered at the boundaries of the water domain.

\section{RESULTS AND DISCUSSION}

An anemometric flow-rate sensor measures a temperature 
drop due to a fluid flow. The velocity and the flow-rate are then deduced from the convective cooling magnitude. Therefore, Joule self-heating and low thermal leakage, i.e. conductive heat loss in the substrate, are mandatory for a high-performance flow-rate sensor. For this reason, glass is usually used as a substrate material for thermal flowrate sensors. For the same reason, silicon is obviously a bad candidate material for such sensors because of its large thermal conductivity. In the present work, we demonstrate that a sensitive silicon based thermal flowrate sensor can be achieved through a geometric optimization which contributes to a reduction in thermal leakage through the substrate.

For comparison sake, we consider four different designs of a flowrate sensor as shown in Error! Reference source not found. (three fabricated prototypes and an optimized prospective design). First, a reference situation with zero velocity fluid is considered. This situation provides information on the joule self-heating magnitude as a function of the injected electric current. Then the temperature drop of the hot wire under a water flow is measured as a function of the flow-rate. Experimental results of these two experiments are shown in Figure 5 (a) and (b), respectively, for the glass substrate, the silicon bulk substrate, and the membrane designs. A small maximal temperature increase, $5.6{ }^{\circ} \mathrm{C}$ and $7.3{ }^{\circ} \mathrm{C}$ is observed for silicon and membrane designs, respectively, with a current intensity as large as $32 \mathrm{~mA}$, i.e. with a power supply as large as $11.26 \mathrm{~mW}$. For the same power supply, the glass substrate sensor exhibits a temperature increase of $67.2^{\circ} \mathrm{C}$. The Joule self-heating at non-flow condition is a critical parameter since it provides information regarding the minimal operating current and insights on the expected sensor sensitivity under a fluid flow. We show in Figure 5(b) the non-dimensional temperature decrease of the same fabricated flowrate sensors under flow-rates up to $200 \mathrm{ml} / \mathrm{s}$. The nondimensional temperature variation is defined as $\Delta \mathrm{T} / \Delta \mathrm{T}_{\max }$ where $\Delta \mathrm{T}$ is the difference between the sensor's heater temperature and room temperature at a given flow-rate and $\Delta \mathrm{T}_{\max }$ is the same temperature difference at zero velocity. $\Delta \mathrm{T} / \Delta \mathrm{T}_{\max }$ quantifies the fluid flow cooling effect. The sensor sensitivity depends on this nondimensional temperature value. The smaller the value of $\Delta \mathbf{T} / \Delta \mathbf{T}_{\max }$, the larger the sensor's sensitivity. However, when $\Delta \mathbf{T} / \Delta \mathbf{T}_{\max }$ reaches zero, the sensor is saturated.

These measurements were conducted at a supplied current of $32 \mathrm{~mA}$ even if the glass substrate device could be operated properly at lower intensities, as low as $13 \mathrm{~mA}$. However, such a low current would not provide sufficient joule self-heating for the two other devices in order to sense the considered flow-rate values. As expected from Figure 5 (a) results, Figure 5(b) shows that the glass substrate sensor is sensitive to the largest flow-rate range, up to $180 \mathrm{ml} / \mathrm{s}$ while the silicon substrate device and the membrane device saturate at flow-rates as low as $50 \mathrm{ml} / \mathrm{s}$. Indeed, at this flow-rate, these two devices are completely cooled down to room temperature. An additional flow-rate increase would not induce an additional temperature variation of the hot wires, hence the observed saturation. Surprisingly, the use of a membrane does not enhance significantly the silicon substrate device performances in spite of the thermal conductance drop induced by the membrane. To overcome the limitation of the silicon substrate and membrane devices, we suggest a new design using a silicon substrate etched at its front face as shown in Figure 4(d). A few hundred- $\mu \mathrm{m}$ wide cavity is created around the platinum hot wire. The cavity is expected to reduce the solid contact between the resistor and the silicon substrate, hence reducing thermal leakage through the substrate.

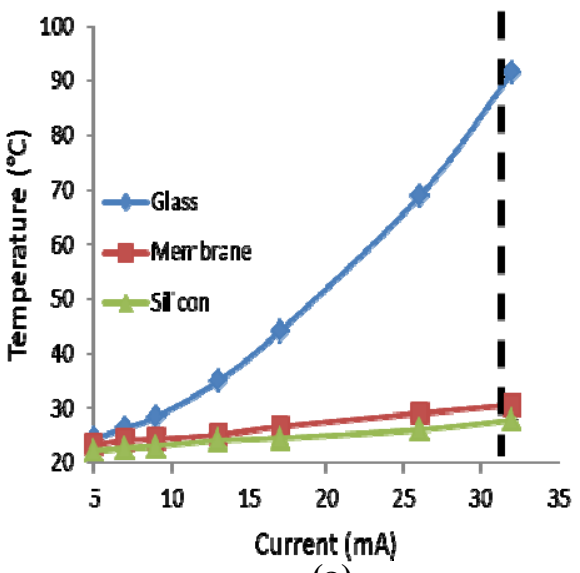

(a)

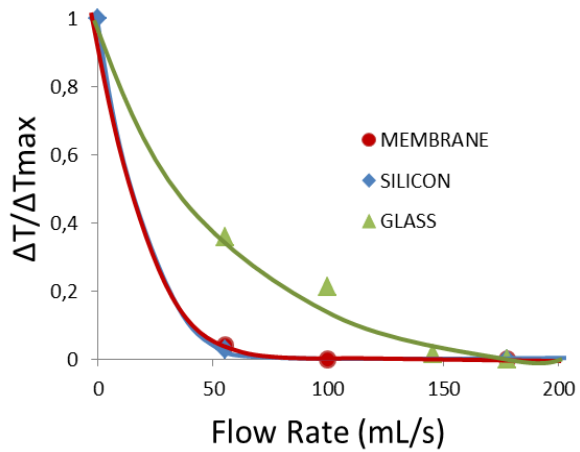

(b)

Figure 5: Experimental results of the resistor temperature at different electric currents (a) and non-dimensional temperature variation at different velocities for the three configurations

This assumption is checked by comparative CFD simulations targeting the best tradeoff between sensitivity and power consumption. The numerical results are presented in Figure $\mathbf{6}$ where we show the nondimensional temperature drop of the fabricated sensors and the proposed new design as a function of the fluid velocity. Simulation are performed for a supply power of $10 \mathrm{~mW}$.

First, the numerical results for the fabricated designs are in a strong agreement with the experiment (Figure 5). Indeed, the glass device is more sensitive than the two others and no significant difference is observed between the silicon bulk substrate and the silicon membrane devices.

In addition, the proposed design shows a larger sensitivity with comparison to silicon bulk substrate and the membrane design while it is based on a silicon substrate. This design show a behavior close to that of the glass based thermal flow-rate sensor. 
Even with the rather high conductivity of silicon, it appears that the thermal conductance can be diminished through the use of an appropriate geometric optimization, the membrane or the comb structure for instance which appears as the most promising configuration. The effect of silicon structuration on the thermal conductance can also be seen as the production of a metamaterial of smaller effective thermal conductivity as compared to bulk silicon.

Finally, it is worth noting a surprising behavior of the comb and glass devices for a flow velocity around $0.2 \mathrm{~m} / \mathrm{s}$ (Figure 6) in the form of an increase of the resistor temperature with an increasing flow-rate instead of monotonic temperature drop. It can be shown through detailed CFD simulations that this unexpected temperature increase is due to a reverse flow at the vicinity of the heater which appears at these velocities and brings back heated water around the resistor. Such a reverse flow is also observed for bulk silicon and silicon membrane devices. However, it does not induce a temperature increase due to the large heat leakage within the substrate and the less important heating of the fluid surrounding the resistor.

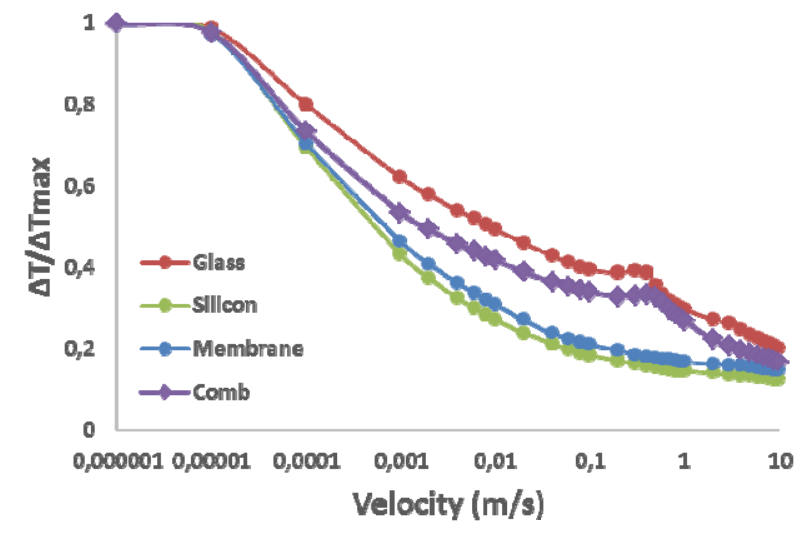

Figure 6: Numerical simulation results for the 4 configurations described in Figure 4. The comb structure exhibits an intermediate sensitivity between glass and membrane based devices.

\section{CONCLUSION AND PROSPECTS}

In this report, we demonstrated the successful monolithic co-integration of a thermal flow-rate sensor with other chemical and MEMS physical sensors. Such cointegration requires the use of silicon as a substrate. Unfortunately, the relatively large thermal conductivity of silicon reduces the performances of the thermal flow-rate sensor. Consequently, the main challenge is to achieve a sensitive low power thermal flow-rate sensor on a silicon substrate. This is achieved through micro-structuration of the silicon substrate using a comb like structure and reducing the substrate overall thermal conductance. Such micro-structuration leads to a silicon based micromachined thermal flow-rate sensor with performances comparable to state of the art devices based on low conductivity materials such as glass.

In the present work, the flow rate sensor was operated independently from the other sensors of the chip. Due to the large number of sensing elements on a very small footprint; cross-interactions between the different sensors is possible and might have an effect on the overall chip performances. The investigation of these cross interactions is the next step of the present work.

\section{ACKNOWLEDGEMENT}

This work has received funding from the European Union's H2020 Programme for research, technological development and demonstration under grant agreement No644852.

Part of this work received the support of the National Research Agency (ANR) in the frame of the EquipEx project SENSE-CITY of the Programme d'Investissements d'Avenir (PIA), involving IFSTTAR and ESIEE Paris as founding members of the consortium. Fabrication of the chips was done in the cleanroom facilities of ESIEE Paris, whose technical staff is deeply acknowledged.

\section{REFERENCES}

[1] J. T. W. Kuo, L. Yu, and E. Meng, "Micromachined Thermal Flow Sensors-A Review," Micromachines, vol. 3, no. 3, pp. 550-573, Jul. 2012.

[2] W.-C. Lin and M. A. Burns, "Low-power microfabricated liquid flow-rate sensor," Anal. Methods, vol. 7, no. 9, pp. 3981-3987, Apr. 2015.

[3] R. Vilares et al., "Fabrication and testing of a SU-8 thermal flow sensor," Sens. Actuators B Chem., vol. 147, no. 2, pp. 411-417, Jun. 2010.

[4] S. Wu, Q. Lin, Y. Yuen, and Y.-C. Tai, "MEMS flow sensors for nano-fluidic applications," Sens. Actuators Phys., vol. 89, no. 1-2, pp. 152-158, Mar. 2001.

[5] H. Fujita, "A decade of MEMS and its future," in , Tenth Annual International Workshop on Micro Electro Mechanical Systems, 1997. MEMS '97, Proceedings, IEEE, 1997, pp. 1-7.

[6] Y. Yamazaki, K. Yoshikawa, and K. Sato, "A MEMS flow sensor applied in a variable-air-volume unit in a building air-conditioning system," Sens. Actuators Phys., vol. 189, pp. 212-217, Jan. 2013.

[7] J. Sun, D. Cui, L. Zhang, X. Chen, H. Cai, and H. Li, "Fabrication and characterization of a double-heater based MEMS thermal flow sensor," Sens. Actuators Phys., vol. 193, pp. 25-29, Apr. 2013. 